\title{
Lateral asymmetry of the Hoffmann reflex: relation to cortical laterality
}

\author{
DAVID J GOODE, STEPHANIE GLENN, ALEXANDER A MANNING, AND \\ JOHN F MIDDLETON \\ From the Bowman Gray School of Medicine of Wake Forest University, Winston-Salem, NC and the \\ Broughton Hospital, Morganton, NC, USA
}

SUMMARY Lateral asymmetry of the Hoffmann reflex (H-reflex) recovery curve was found in seven subjects with no personal or family history of neurological or psychiatric disorder. Differences between recovery curves from the right and left leg were larger than differences in the same leg on two successive test days. In a group of 27 psychiatric inpatients, lateral asymmetry of the later portion of the recovery curve was correlated with cortical laterality, as measured by selective identification of differing verbal stimuli presented simultaneously to both ears (DL) and to total laterality scores, a sum of visual half-field, DL, and motor laterality scores. Asymmetry of the recovery curve is related in part to cortical laterality, possibly through selective activation of cortical motor centres on the preferred side.

The Hoffmann reflex (H-reflex) is a monosynaptic spinal reflex elicited by electrical stimulation of the posterior tibial nerve, recorded as an electromyographic response of the gastrocnemius-soleus muscle group. ${ }^{2}$ The amplitude of the $H$-reflex is related to $\alpha$-motor neuron excitability, ${ }^{3}$ but absolute amplitude is affected by electrode placement and skin and tissue resistance. The ratio of the maximum $\mathrm{H}$-reflex to the maximum directly elicited or M-response (H/M ratio) has been proposed as a better measure of $\mathrm{H}$-reflex activity. ${ }^{45}$ However, the $\mathrm{H} / \mathrm{M}$ ratio is poorly correlated with measures of spasticity. ${ }^{5}$

The H-reflex recovery curve is a record of the effect of a conditioning stimulus on the H-reflex produced by a second stimulus of equal intensity. ${ }^{6} 7$ The time interval between the conditioning and the stimulus pulses is plotted against the amplitude of the H-reflex to generate the recovery curve of the H-reflex. The recovery curve is a more sensitive measure of changes in $\alpha$-motor neuron excitability than $\mathrm{H}$-reflex amplitude or the $\mathrm{H} / \mathrm{M}$ ratio. ${ }^{8}$ Changes in the H-reflex recovery curve have been reported in Parkinson's Disease ${ }^{9-12}$ and spasticity secondary to upper-motor neuron lesions. ${ }^{910} 13$ In all of these studies, measurements were made on one

Address for reprint requests: Dr DJ Goode, Bowman Gray School of Medicine, Winston-Salem, N Carolina 27103, USA.

Accepted 11 April 1980 side. Garcia-Mullin and Mayer ${ }^{14}$ found alterations in the recovery curve on the hemiplegic side in patients with unilateral vascular uppermotor neuron lesions. They also found changes in the recovery curve on the unaffected side, but usually it is assumed that the H-reflex, like other monosynaptic reflexes is bilaterally symmetrical in normal subjects.

We report asymmetries in the H-reflex recovery curve in seven normal subjects with no personal or family history of neuromuscular disease. Parallel measurements of H-reflex recovery curve and cortical laterality were made simultaneously in a group of 20 psychiatric patients, before and during treatment with three antipsychotic drugs. We found a correlation of cortical laterality with lateralisation of the Hoffmann reflex in these subjects.

\section{Methods}

Seven normal subjects, three male and four female, ranging in age from 21 to 24 years, were screened for a personal or family history of neuromuscular disease or mental illness, or personal history of significant back or leg trauma, and preferred handedness was established. They were tested on two occasions, at least 24 hours apart, the sum of the differences between the right and left legs on both testing occasions was compared by Student's $t$-test for paired data 
to the difference between tests summed for both legs for each parameter.

Twenty-seven psychiatric patients with a local diagnosis of schizophrenia or schizo-affective disorder refractory to treatment were admitted to the Clinical Research Unit of Broughton State Hospital for study of the effects of three antipsychotic drugs (thiothixene, loxipene, and molindone). Measures of the Hoffman reflex recovery curve, and of cortical laterality, were performed in the absence of drugs, (five days after withdrawal of oral medication), and was repeated after one month of treatment with each of the three antipsychotic agents. Repeated measures of cortical laterality are more accurate, so we selected the second and the equivalent Hoffman reflex when this was available. Eighteen of the 27 patients were tested repeatedly, and the second test was used for this study (initial measures were used for the remaining nine patients).

The method for measurement of the recovery curve has been described previously. ${ }^{15}{ }^{16}$ Subjects were tested while reclining in a lounge chair with the tested leg supported at the ankle by a rolled towel. Beckman silver-silver chloride recording electrodes were placed 2 to $4 \mathrm{~cm}$ apart over the lower gastrocnemius and soleus muscles, and a ground electrode was strapped over the upper posterior calf. The stimulating electrodes were fixed over the posterior tibial nerve in the popliteal fossa. Square-wave stimulus pulses 1 $\mathrm{ms}$ in duration were delivered to the posterior tibial nerve. At the stimulus voltage for the maximum $\mathrm{H}$-response, paired stimuli were delivered at intervals from 30 to $1000 \mathrm{~ms}$, with one minute intervals between stimulations. The ratio of the amplitude of the $\mathrm{H}$-reflex produced by the second stimulus pulse $\left(\mathrm{H}_{2}\right)$ to the amplitude of the $\mathrm{H}$-reflex produced by the first stimulus pulse $\left(\mathrm{H}_{1}\right)$ expressed as a percent $\left(\mathrm{H}_{2} / \mathrm{H}_{1} \%\right)$, was estimated. The recovery curve was produced by plotting $\mathrm{H}_{2} / \mathrm{H}_{1} \%$ against stimulus interval.

Three parameters of the recovery curve selected for analysis: (A) the maximum value of $\mathrm{H}_{2} / \mathrm{H}_{1} \%$ over the stimulus intervals from 50 to $300 \mathrm{~ms}$; (B) the mean value of $\mathrm{H}_{2} / \mathrm{H}_{1} \%$ over stimulus intervals 50 to $300 \mathrm{~ms}$; and $(\mathrm{C})$ the mean value of $\mathrm{H}_{2} / \mathrm{H}_{1} \%$ over stimulus intervals 400 to $800 \mathrm{~ms}$. These parameters are illustrated on a normal recovery curve in fig 1 . Overall recovery was estimated by summing parameters $B$ and C. Recovery curve lateralisation coefficients were obtained by subtracting the value of each parameter of the left leg from that of the right leg.

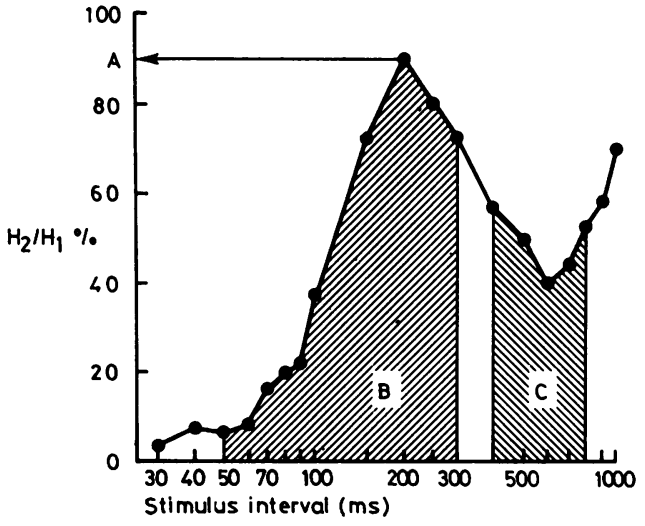

Fig 1 Normal recovery curve with illustration of parameters studied. Parameter $A$ is the maximum value of $\mathrm{H}_{2} / \mathrm{H}_{1} \%$ over stumulus intervals 50 to $300 \mathrm{~ms}$.

Parameter $\mathrm{B}$ is the mean of $\mathrm{H}_{2} / \mathrm{H}_{1} \%$ over stimulus intervals 50 to $300 \mathrm{~ms}$. Parameter $C$ is the mean value of $\mathrm{H}_{2} / \mathrm{H}_{1} \%$ over stimulus intervals 400 to $800 \mathrm{~ms}$.

Three measures of cortical laterality were performed at the time of recovery curve testing in all psychiatric patients. Visual half-field (VHF) measurement was based on selective recognition of 40 four-letter word stimuli exposed simultaneously to the right and left visual fields. Dichotic listening (DL) measurement was based on recognition of monosyllabic nouns presented simultaneously to the right and left ears by stereophonic earphones. Motor laterality (ML) was derived from observations of handedness in 11 common motor activities, finger tapping speed, and manual dexterity (Crawford Small Parts Dexterity Test-Part I). VHF, DL, and ML results were quantitated by means of an index ranging from -1 to +1 with a positive score indicating a right-sided (left-cortical) advantage. A total laterality score was computed by adding the VHF, DL, and ML indices. Hreflex and psychological tests were performed by different individuals who were unaware of other test results.

\section{Results}

There were differences between the recovery curves measured from the right and left leg in normal subjects (fig 2). To determine whether this asymmetry represented a systematic difference between the right and left side, recovery curve measures were repeated on a second testing day. Differences between the left and right sides persisted in all five subjects. If the recovery 


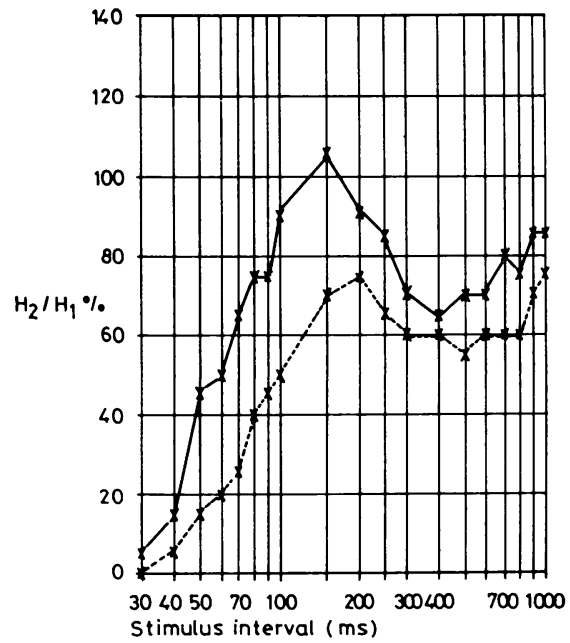

Fig 2 H-reflex recovery curve from right leg (solid line) and left leg (dashed line) of a normal subject

curve of the left leg was higher than that of the right, it remained higher than the right on repeated testing in all subjects.

Differences between the right and left side were compared to differences in the same leg between repeated testing (table 1). Lateral differences were larger than differences between tests for the same leg for each of the three parameters studied. All control subjects tested expressed right hand preference. Of the seven subjects tested, three had higher recovery curves in the right leg, and four had higher recovery in the left leg.

Table 2 presents correlation coefficients relating coefficients of lateralisation for the three parameters of the H-reflex recovery curve to the measures of cortical laterality in the 27 psychiatric patients. Coefficients of lateralisation for parameters $C$ were correlated with both DL and total measures of cortical laterality. Coefficients of lateralisation for parameters A and B
Table 2 Relation of recovery curve lateralisation to conventional measures of cortical laterality. (Pearson correlation coefficients are presented relating lateralisation coefficients of each recovery curve parameter to indices of laterality.)

\begin{tabular}{lllll}
\hline $\begin{array}{l}\text { Recovery } \\
\text { curve } \\
\text { parameter }\end{array}$ & $\begin{array}{l}\text { Cortical } \\
\text { laterality } \\
\text { index }\end{array}$ & $\begin{array}{l}\text { Correlation } \\
\text { coefficient }\end{array}$ & $N$ & Significance \\
\hline A & VHF & -.0784 & 22 & NS \\
& DL & .0925 & 27 & NS \\
& TOTAL & -.0999 & 21 & NS \\
& VHF & -.2779 & 22 & NS \\
& DL & -.0456 & 27 & NS \\
C & TOTAL & -.1144 & 21 & NS \\
& VHF & -.2895 & 22 & NS \\
& DL & -.3826 & 27 & p $<0.05$ \\
C + F & TOTAL & -.4245 & 21 & p $<0.05$ \\
& VHF & -.3327 & 22 & NS \\
& DL & -.2105 & 27 & NS \\
& TOTAL & -.2868 & 21 & NS \\
\hline
\end{tabular}

were not correlated with any of the measures of cortical laterality. Coefficients of lateralisation for the sum of parameters $C$ and $F$, an estimate of total recovery curve height, were not correlated with measures of laterality and total laterality scores.

\section{Discussion}

We have found significant lateral asymmetries in the H-reflex recovery curve in a group of normal subjects without history of neurological disease, an asymmetry that persisted on repeated testing. The difference between the right and left leg was greater than that of repeated measurement of the same leg, indicating that this observation is not an artifact. (Lateral differences in the H-reflex have not been described in normal subjects, although lateral differences have been reported in a study of patients with unilateral upper motor neuron lesions, in which asymmetry of the recovery curve was assumed to be one neurological abnormality. ${ }^{14}$ )

These data from the H-reflex recovery curve provide evidence for a persistent lateral asym-

Table 1 Statistical comparison by t-test for paired data of test-retest differences and right-left differences in $H$-reflex recovery curve parameters

\begin{tabular}{|c|c|c|c|c|}
\hline & $\begin{array}{l}\text { Mean difference between } \\
\text { test } \pm S D\end{array}$ & $\begin{array}{l}\text { Mean difference between } \\
\text { right and left side } \pm S D\end{array}$ & $t$ & $p$ \\
\hline $\begin{array}{l}\text { A. Maximum value } \mathrm{H}_{2} / \mathrm{H}_{1} \% \text { over } \\
\text { stimulus interval } 50 \text { to } 300 \mathrm{~ms}\end{array}$ & $32 \cdot 86 \div 19 \cdot 76$ & $50 \cdot 00 \pm 20 \cdot 41$ & $3 \cdot 0317$ & 0.05 \\
\hline $\begin{array}{l}\text { B. Mean value } \mathbf{H}_{2} / \mathbf{H}_{1} \% \text { over } \\
\text { stimulus interval } 50 \text { to } 300 \mathrm{~ms}\end{array}$ & $19 \cdot 00 \pm 8 \cdot 29$ & $31 \cdot 86 \pm 16 \cdot 43$ & $2 \cdot 1667$ & NS \\
\hline $\begin{array}{l}\text { C. Mean value } \mathrm{H}_{2} / \mathrm{H}_{1} \% \text { over } \\
\text { stimulus interval } 400 \text { to } 800 \mathrm{~ms}\end{array}$ & $14 \cdot 71 \pm 5 \cdot 22$ & $29 \cdot 00 \pm 19 \cdot 66$ & $2 \cdot 2672$ & NS \\
\hline Parameter P \& C & $33 \cdot 71 \pm 6 \cdot 26$ & $60 \cdot 86 \div 24 \cdot 31$ & $3 \cdot 2382$ & 0.05 \\
\hline
\end{tabular}


metry of $\alpha$-motor neuron excitability in normal subjects. There are a limited number of reasons for these findings: (1) asymmetry of input from peripheral receptors, particularly muscle spindles, which could be altered by asymmetric activation of the gamma-motor system, (2) asymmetry in intrinsic excitability of the $\alpha$-motor neuron in the spinal cord, (3) asymmetry in activity of spinal interneurons, or (4) asymmetry of input from higher centres. Although there is not full agreement, ${ }^{17}$ the recovery curve is believed to be affected by input from higher centres as shown by abnormalities of the recovery curve occurring in patients with Parkinson's Disease $^{912}$ and their correction by thalamotomy." Cortical motor centres also affect the recovery curve, as abnormalities are found after upper motor neuron lesions. ${ }^{910} 13$

It is possible asymmetries in H-reflex recovery curve are related to cortical dominance. However, no clear relationship was observed between preferred handedness and recovery curve asymmetry in the control subjects studied. Preferred handedness alone is not, however, reliable as a predictor of cortical laterality. ${ }^{18}$ Simultaneous measures of cortical laterality using different outputs (VHF, DL, and ML testing) were compared to H-reflex asymmetries in 20 psychiatric inpatients. Asymmetries of the later portion of the recovery curve (parameter C) were correlated with DL measures of cortical laterality and total laterality scores. In each relation, lower recovery curves were found on the preferred side. This is of interest in that patients with an upper-motor neuron lesion, as well as those with Parkinson's Disease, have an elevation of the recovery curve in the corresponding leg. ${ }^{91214}$ Previous work ${ }^{15} 16$ has shown that the severity of psychiatric abnormality is correlated with recovery curve elevation in patients with chronic schizophrenia.

A contemporary theory of cortical laterality suggests that selective hemispheric activation may play a role in the determination of laterality. ${ }^{19-21}$ Our observations are consistent with this hypothesis, if one assumes that cortical activation is associated with lowering of the recovery curve on the preferred side. Cortical dysfunction has been shown to be related to elevation of the recovery curve, ${ }^{14}$ but direct evidence for lowering of the recovery curve related to cortical activation is not available. Recent work in laboratory animals has demonstrated that subcortical concentrations of biogenic amines may determine laterally asymmetries. ${ }^{22}{ }^{23}$ These data suggest that subcortical, as well as cortical, lateral differences may contribute to recovery curve asymmetries.

Asymmetry of some degree was found in both control and patient subjects. Since all subjects were carefully screened to eliminate a history or neurological or muscle disease or trauma to legs or back, the asymmetries found must represent a physiological process. Therefore, caution should be exercised in interpreting lateral asymmetry of the H-reflex recovery curve, for such asymmetry does not necessarily indicate a pathologic process. Further study is indicated to elucidate the physiological basis for these findings.

This work was supported in part by the small grants program of the North Carolina Division of Mental Health/Mental Retardation and by the North Carolina United Way. Grateful acknowledgement is made to the staff of the Clinical Research Unit at Broughton Hospital for conscientious care of the patients studied and to $\mathrm{Mr}$ Bob Condor and Steve Henson who performed most of the testing.

\section{References}

1 Hoffman P. Untersuchungen uber die refraktare Periode des menschlichen Ruckenmarkes. $Z$ Biologie 1924; 81:37-48.

2 Hugon M. Methodology of the Hoffmann reflex in man. New Dev Electromyog Clin Neurophysiol 1973; 3:277-93.

3 Magladery JW, Teasdall RD, Park AM, Languth HW. Electrophysiological studies of reflex activity in patients with lesions of the nervous system: I. A comparison of spinal motoneurone excitability following afferent nerve volleys in normal persons and patients with upper motor neurone lesions. Bulletin of the Johns Hopkins Hospital 1952; 91:219-44.

4 Angel RW, Hoffman WW. The H-reflex in normal, spastic, and rigid subjects. Arch Neurol $1963 ; 8: 591-6$.

5 Matthews WB. Ratio of maximum H-reflex to maximum $M$ response as a measure of spasticity. J Neurol Neurosurg Psychiatry, 1966; 29:201-4.

6 Magladery JW, Teasdall RD, Park AM, Porter WE. Electrophysiological studies of nerve and reflex activity in normal man: V. Excitation and inhibition of two-neurone reflexes by afferent impulses in the same nerve trunk. Bulletin of the Johns Hopkins Hospital 1951; 88:520-61.

7 Magladery JW, Teasdall RD, Park AM, Languth HW. Some mechanisms in man suppressing spinal motoneurone excitability. Trans Am Neurolog Assoc 1952; 77:100-5.

8 Diamantopoulos E, Olsen PZ. Motoneurone excitability in normal subjects and patients with 
abnormal reflex activity. In: Proceedings of the Sixth International Congress of Electroencephalgraphy and Clinical Neurophysiology, New York, American Elsevier, 1965, 621-3.

9 Olsen PZ, Diamantopoulos E. Excitability of spinal motor neurones in normal subjects and patients with spasticity, Parkinsonian rigidity, and cerebellar hypotonia. J Neurol Neurosurg, Psychiatry 1967; 30:325-30.

10 Takamori M. H-reflex study in upper motor neuron diseases. Neurology 1967; 17:32-40.

11 Laitinen LV, Ohno Y. Effects of thalamic stimulation and thalamotomy on the H-reflex. Electroencephalography and Clinical Neurophysiology 1970; 28:586-91.

12 Sax DS, Johnson TL, Feldman RG. L-dopa effects on H-reflex recovery in Parkinson's Disease. Ann Neurol 1977; 2:120-4.

13 Yap CB. Spinal segmental and long-loop reflexes on spinal motoneurone excitability in spasticity and rigidity. Brain 1967; 90:887-96.

14 Garcia-Mullin R, Mayer RF. H-reflexes in acute and chronic hemiplegia. Brain 1972; 95:559-72.

15 Goode DJ, Meltzer HY, Crayton JW, Mazura TA. Physiologic abnormalities of the neuromuscular system in schizophrenia. Schizophr Bull
1977; 3:121-38.

16 Goode DJ, Meltzer HY, Mazura TA. H-reflex abnormalities in psychotic patients. Biol Psychiatry 1979; 14:95-110.

17 Masland WS. Facilitation during the H-reflex recovery cycle. Arch Neurol 1972; 26;313-19.

18 Davis AE, Wada JA. Speech dominance and handedness in the normal human. Brain Lang 1978; 5:42-55.

19 Kinsbourne M. Cerebral basis of asymmetries in attention. Acta Psychol (Amst) 1970; 33:193-201.

20 Kinsbourne $M$. The control of attention by interaction between the cerebral hemispheres. In: Kornblum S, ed. Attention and Performance, IV. New York: Academic Press, 1973.

21 Kinsbourne $M$. The mechanism of hemispheric control of the lateral gradient of attention. In: Rabbit P, Dornic S, eds. Attention and Performance, V. London: Academic Press, 1975.

22 Narasimhachari N, Smith RC, Samorajski R, Davis JM. Regional distribution of dopamine metabolites in the caudate of rat and rhesus monkey. Society for Neuroscience 1977; p 43.

23 Mandell AJ, Knapp S. Asymmetry and mood, emergent properties of serotonin regulation. Arch Gen Psychiatry 1979; 36:909-16. 